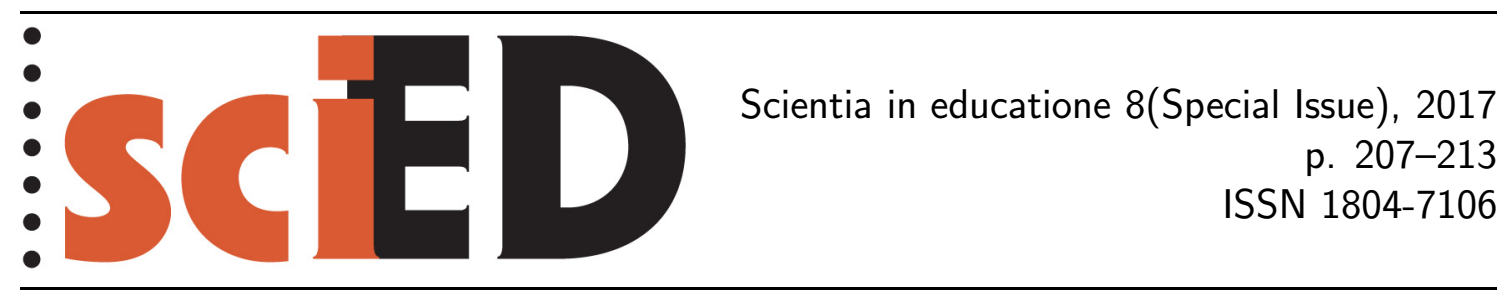

\title{
Inquiry Based Science Education and Getting Immediate Students' Feedback about Their Motivation
}

\author{
Martina Kekule, Vojtech Zak, Zuzana Jeskova, \\ Katarina Kimakova, Maria Ganajova, Marian Kires
}

\begin{abstract}
The paper is based on collecting evidence of the Establish project impact on students. For the purpose two questionnaires based on the existing tools have been used. Questionnaire 1 is a part of Intrinsic Motivation Inventory (IMI) based on the Self-determination theory. It is aimed at assessing students' interests, their perceived choice and usefulness of implemented learning units and should be answered after each learning unit/several IBSE activities. Several items of CLES questionnaire are included there as well. Questionnaire 2 assesses the impact on students' attitudes towards science and technology and on their knowledge about nature of building up science knowledge. Both questionnaires exist in the lower and upper secondary school versions. The paper presents selected data and results which were obtained by addressing the Questionnaire 1, so that the focus is on getting students' feedback about their intrinsic motivation. Our assumption is that active learning is associated with positive intrinsic motivation of students. That is why we find as very important that educators have a possibility to understand the phenomenon more deeply. We aim to present the reliable tool for getting the feedback and to present a way of data processing which does not need advanced statistical methods, so that teachers (as well as science education researchers) can use and analyze data obtained by the tool. Means and standard deviations for items of the subscales Interest/Enjoyment, Perceived choice and Value/Usefulness were computed. To determine the consistency of results, the Standard Pearson correlation coefficient was computed for all items within the subscales. Based on the findings, we can conclude that participants' answers (questionnaire results) were consistent (not responded mechanically).
\end{abstract}

Key words: students' feedback, motivation, questionnaire, IBSE. 


\section{INTRODUCTION}

The paper is focused on getting students' feedback about their motivation just after their science lessons led by inquiry teaching method. The presented fast feedback tool has been used during the ESTABLISH project (n.d.). The objective of the project (funding from the European Community's Seventh Programme [FP7/2007-2013] under grant agreement no. 244749) is the wide use and dissemination of inquiry-based teaching method for science education (IBSE) at secondary schools across Europe. Over the course of the project, a number of ESTABLISH teaching and learning materials (units) have been developed and adapted for the use in classrooms in participating countries. The rationale for ESTABLISH lies in creating authentic learning environments for science by bringing together and involving all relevant stakeholders, particularly the scientific and industrial community, policy makers, parents, science education researchers and teachers to drive change in the classroom.

For collecting evidence of the impact of the Establish project on students two questionnaires based on the existing tools have been used. Questionnaire 1 is a part of Intrinsic Motivation Inventory (IMI) (n.d.) based on the Self-determination theory developed by Ryan and Deci (2000). It is aimed at assessing students' interests, their perceived choice and usefulness of implemented learning units and should be answered after each learning unit/several IBSE activities. Several items of CLES questionnaire (Fraser, Taylor \& White, 1994) are included there as well. Questionnaire 2 assesses the impact on students' attitudes towards science and technology and on their knowledge about nature of building up science knowledge. Both questionnaires exist in the lower and upper secondary school versions (12-15/16-19 year-old students).

The paper presents chosen data and results which were obtained by addressing the Questionnaire 1 (when assigning to students from Slovakia), so that the focus is on getting students' feedback about their intrinsic motivation. Our assumption is that active learning is associated with positive intrinsic motivation of students. That is why we find as very important that educators have a possibility to understand the phenomenon more deeply. We aim to present the reliable tool for getting the feedback and to present a way of data processing which does not need advanced statistical methods, so that teachers (as well as science education researchers) can use and analyze data obtained by the tool.

\section{More ABOUt THE QUESTIONNAIRES}

As it is stated in the introductory part, the questionnaire focused on getting immediate feedback includes prevalently parts of Intrinsic Motivation Inventory (IMI). The inventory consists altogether of 45 items which belong to 7 subscales (dimensions). The statistical characteristics of the inventory allow to a researcher to create her/his own questionnaire where she/he includes just items belonging to the dimensions which she/he is interested in. Mainly because of the time limit (we needed a tool for the fast feedback), we chose for our tool just items concerning three dimensions: interest/enjoyment, value/usefulness and perceived choice. "The interest/enjoyment subscale is considered the self-report measure of intrinsic motivation, the other two dimensions are theorized to be positive predictors" (Intrinsic Motivation Inventory, n.d.). 
The dimension Interest/Enjoyment measures to what extent students like the performed activity and find it interesting. The dimension Perceived Choice measures to what extent students perceive their choice when performing a given activity. The dimension Value/Usefulness measures how students perceive the value/usefulness of a given activity for themselves. The form of an item is a statement which students assess as a true or not true. For the assessment they use 7 point scale:

$$
1-2-3-4-5-6-7
$$

not at all true $-\ldots-$ somewhat true $-\ldots-$ very true

Some items express very similar content what was perceived by some students as annoying. However, it is necessary when we need to judge if students really assessed the statement or if they only put marks by chance. This consistency in students' responses will be discussed later.

The second part of the questionnaire is based on the CLES questionnaire - the Constructivist Learning Environment Survey. In the section we are focused on ways of students' communication during the activities as an aspect of social interaction that can influence motivation in general as well. The questionnaire origins from the constructivist theory and is widely used for evaluating lessons from this perspective. We used a part of the questionnaire which contains 6 items focusing on students' communication during the activity (e.g. passivity or activity in the initiation of communication). Students assess how often they communicate using 5 point scale.

\section{DESCRIPTION OF THE TOOL}

Our questionnaire is intended to be used as a fast feedback after the learning unit and it will be assigned immediately after the unit (at the end of the lesson). It takes about 10 minutes to complete this questionnaire. The questionnaire exists in a version for lower (marked B, about 12 to 15 year-old, ISCED 2), and upper (marked A, about 16 to 19 year-old, ISCED 3) secondary schools.

\section{QUESTIONNAIRE A — FOR UPPER SECONDARY SCHOOLS}

It contains 25 items with the 7 point scale adopted from the IMI and it focuses on assessing the three discussed dimensions (subscales).

Interest/Enjoyment subscale shows the extent to which students like the performed activity and find it interesting. This subscale comprises a total of 8 items, namely $3,5,7,11,12-\mathrm{R}, 15,17$, and 23 . The " $\mathrm{R}$ " with item no. 12 means that a reverse score is needed. It is an item with the opposite meaning to the other items. It is possible to gain 56 points in total.

Perceived Choice subscale shows how students perceive their choice when performing a given activity. This subscale comprises a total of 8 items, namely $2,8-\mathrm{R}$, 9, 14-R, 18-R, 20-R, 22, and 24-R. The " $R$ " means again that a reverse score is needed and it is possible to gain 56 points in total as well.

Value/Usefulness subscale shows how students perceive the value/usefulness of a given activity for themselves. This subscale comprises a total of 9 items, namely $1,4,6,10,13,16,19,21$, and 25 . It is possible to gain 63 points in total.

The second part of the questionnaire was taken from the CLES. It contains 6 items and it is possible to gain 30 points in total. 
As an example, we present below which items the subscale Interest/Enjoyment consists of:

- While I was doing activities in the learning unit, I was thinking about how much I enjoyed it. (3)

- Activities in the learning unit were fun to do. (5)

- I enjoyed doing activities in the learning unit very much. (7)

- I felt like I was enjoying activities while I was doing them. (11)

- I thought these were very boring activities. (12-R)

- I thought this was a very interesting learning unit. (15)

- I would describe activities in the learning unit as very enjoyable. (17)

- I would describe activities in the learning unit as very fun. (23)

We can see that all eight items express the same (or a very similar) thing: the extent to which students like the performed activity (or the learning unit) and find it interesting, in other words whether the learning unit (activities included in it) was interesting/enjoyable/not boring. The item no. 12-R is reverse ("negative").

\section{QUESTIONNAIRE B — FOR LOWER SECONDARY SCHOOLS}

This version contains 17 items with the 7 point scale adopted from the IMI and it focuses on assessing the two following dimensions: Interest/Enjoyment and Value/Usefulness.

Interest/Enjoyment subscale shows the extent to which students like the performed activity and find it interesting. This subscale comprises a total of 8 items, namely $2,4,6,8,9-\mathrm{R}, 11,13$, and 16 . The "R" with item no. 9 means that a reverse score is needed. It is possible to gain 56 points in total.

Value/Usefulness subscale shows how students perceive the value/usefulness of a given activity for themselves. This subscale comprises a total of 9 items, namely $1,4,6,10,13,16,19,21$, and 25 . It is possible to gain 63 points in total.

The second part of the questionnaire was taken from the CLES. It contains 6 items and it is possible to gain 30 points in total.

The above mentioned research tools are available on the web page (Kekule \& Žák, n.d.).

\section{AN EXAMPLE OF DATA PROCESSING}

\section{BASIC INFORMATION — MEANS OF SELECTED ITEMS}

As an example of basic data processing, we present a part of the Slovak study which includes approx. 1500 students. We are focusing on the dimension Interest/Enjoyment (Questionnaire A, upper secondary schools). As mentioned above, it includes 8 items, namely 3, 5, 7, 11, 12-R, 15, 17, and 23. Means (and standard deviations) were computed using software Statistica (see Table 1 and Figure 1), however, e.g. Microsoft Excel can be recommended as well.

The scale has a range from 1 to 7 , thus, the average is 4 . We can see from the table and the graph that direct items (no. 3, 5, 7, 11, 15, 17, and 23) are assessed positively (nearly 5 on the scale) whereas the only reverse item (no. 12) 
Table 1: Means and standard deviations for items of Interest/Enjoyment dimension

\begin{tabular}{l|c|c}
\hline \multirow{2}{*}{ Variable } & \multicolumn{2}{|c}{$\begin{array}{c}\text { Descriptive Statistics } \\
\text { (Date Slovakia_1A.sta) }\end{array}$} \\
\cline { 2 - 3 } & Mean & Std. Dev. \\
\hline Part1_3 & 4.75 & 1.55 \\
\hline Part1_5 & 4.99 & 1.57 \\
\hline Part1_7 & 4.90 & 1.55 \\
\hline Part1_11 & 4.82 & 1.53 \\
\hline Part1_12R & 2.79 & 1.67 \\
\hline Part1_15 & 4.96 & 1.46 \\
\hline Part1_17 & 4.89 & 1.54 \\
\hline Part1_23 & 4.80 & 1.56 \\
\hline
\end{tabular}

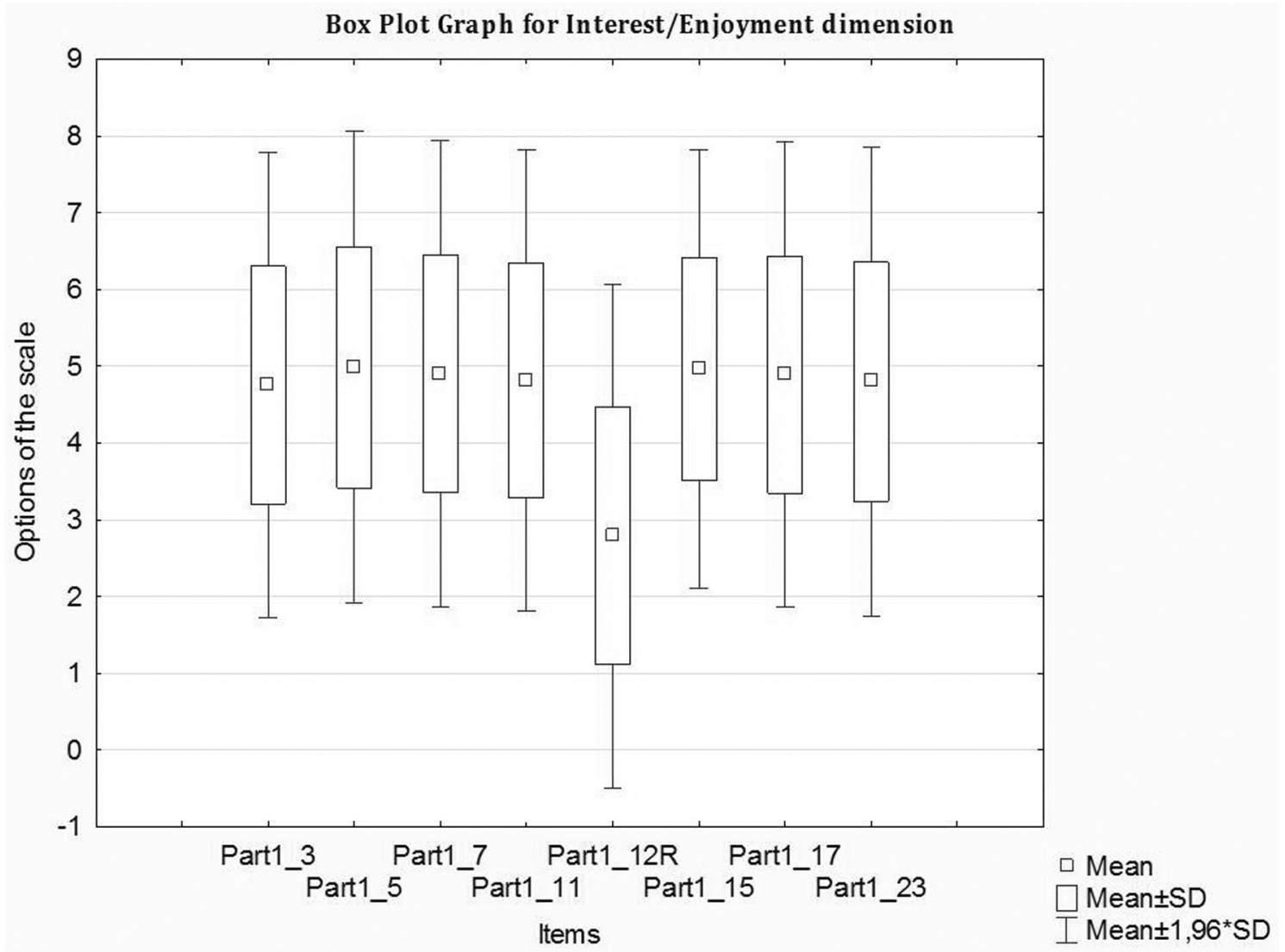

Figure 1: Box Plot Graph for Interest/Enjoyment dimension

negatively (approx. 3 on the scale). We can conclude that students assessed the learning unit (activities included in it) as rather interesting/enjoyable. We can also notice that students were consistent in their evaluation because they assessed direct items positively and the reverse item negatively. The opinion expressed by students can be considered as reliable (more details below).

\section{MORE DETAILED INFORMATION — CONSISTENCY OF RESUlTS}

Based on the fact that each of three dimensions (subscales) mentioned above consists of several similar items (and reverse items as well), we can explore whether students really assess the statement or if they only put marks by chance. In other words, we can explore whether students respond the items seriously (consistently) or not. 
Table 2: Standard Pearson correlation coefficient for Interest/Enjoyment dimension

\begin{tabular}{l|r|r|r|r|r|r|r|r}
\hline & \multicolumn{6}{l}{$\begin{array}{l}\text { Correlations (Date Slovakia_1A.sta) } \\
\text { Marked correlations are significant at } p<0.05000 \\
\text { Variable }\end{array}$} \\
\cline { 2 - 11 } & Part1_3 & Part1_5 & Part1_7 & Part1_11 & Part1_12R & Part1_15 & Part1_17 & Part1_23 \\
\hline Part1_3 & 1.000000 & 0.763765 & 0.762522 & 0.782930 & -0.524958 & 0.716731 & 0.733328 & 0.688135 \\
\hline Part1_5 & 0.763765 & 1.000000 & 0.816786 & 0.807440 & -0.558890 & 0.745488 & 0.756493 & 0.756527 \\
\hline Part1_7 & 0.762522 & 0.816786 & 1.000000 & 0.807380 & -0.545114 & 0.768743 & 0.778445 & 0.764461 \\
\hline Part1_11 & 0.782930 & 0.807440 & 0.807380 & 1.000000 & -0.589269 & 0.762909 & 0.789213 & 0.760800 \\
\hline Part1_12R & -0.524958 & -0.558890 & -0.545114 & -0.589269 & 1.000000 & -0.567658 & -0.534214 & -0.518259 \\
\hline Part1_15 & 0.716731 & 0.745488 & 0.768743 & 0.762909 & -0.567658 & 1.000000 & 0.785376 & 0.760059 \\
\hline Part1_17 & 0.733328 & 0.756493 & 0.778445 & 0.789213 & -0.534214 & 0.785376 & 1.000000 & 0.792286 \\
\hline Part1_23 & 0.688135 & 0.756527 & 0.764461 & 0.760800 & -0.518259 & 0.760059 & 0.792286 & 1.000000 \\
\hline
\end{tabular}

To determine this characteristic - consistency of results - Standard Pearson correlation coefficient was computed (using software Statistica, see Table 2; Microsoft Excel enables users to compute correlation coefficients as well).

We can see from the table that values of the correlation coefficient are from 0.69 to 0.82 between direct items and from -0.52 to -0.59 between the reverse and direct items. All correlations are statistically significant at $p<0.05$. Thus in both cases, we can speak about a high correlation. Based on this findings, we can conclude that students' answers (questionnaire results) are consistent. They express students' opinion repeatedly in the same (or a very similar) way, so we can assume that it is meant seriously.

\section{Conclusions}

Our assumption is that active learning is associated with positive intrinsic motivation of students. That is why we have presented the tool for getting students' feedback after learning lessons. The investigated lessons were taught by inquiry based teaching method (IBSE) according to learning units created within the ESTABLISH project. The assessment tools are available in English version on the web page (Kekule \& Žák, n.d.) for both teachers and researches. Their administration takes about 10 minutes, so that it is appropriate in relation to the time of the typical learning unit.

The above presented example of results was obtained by using software Statistica. We recommend this program, especially for research purposes, however, other common statistical programs can be used for gaining results intended for teaching and learning purposes as well, e.g. MS Excel. In other words, the data processing does not need advanced statistical methods, so that teachers (as well as science education researchers) can analyse data obtained using the tool by themselves.

Besides the common basic statistics (mainly means and standard deviations), the way how to determine consistency of results was presented. In case of the high correlation between items related to the same dimension, we can speak about the high consistency of findings. Thus, we can conclude that students' opinions are meant seriously. The presented tool enables teachers and researchers to gather and distinguish reliable data. In this case, the tool can be considered as a reliable tool. 


\section{REFERENCES}

Deci, E. L. \& Ryan, R. M. (2000). Self-determination theory and the facilitation of intrinsic motivation, social development, and well-being. American Psychologist, 55, 68-78. Available at

http://www.selfdeterminationtheory.org/questionnaires/10-questionnaires/50

ESTABLISH project. (n.d.). Available at http://www.establish-fp7.eu

Fraser, B. J., Taylor, P. C. \& White, L. R. (1994). CLES: An instrument for monitoring the development of constructivist learning environments. Paper presented at the annual meeting of the American Educational Research Association, New Orleans.

Intrinsic Motivation Inventory (IMI). (n.d.). Available at http://www.selfdeterminationtheory.org/questionnaires/10-questionnaires/50

Kekule, M. \& Žák, V. (n.d.). Research tools, tools for the Establish project. Available at http://kdf.mff.cuni.cz/vyzkum/tools.php

MARTINA KEKULE

VOJTECH ZAK

Faculty of Math. and Physics, Charles University, Prague, Czech Republic

ZuZANA JESKOVA

KATARINA KIMAKOVA

Maria Ganajova

MARIAN KIRES

Faculty of Science, Pavol Jozef Safarik University, Kosice, Slovak Republic 